\title{
Pengembangan material Reusable Concrete untuk 3DP Building
}

\author{
Andy Nurul Yunita Pettalolo*, Ibnu Abdul Rosid, Alva Edy Tontowi \\ Jurusan Teknik Industri, Departemen Teknik Mesin dan Industri \\ Fakultas Teknik Universitas Gadjah Mada \\ Email Korespondensi : *andynurul94@mail.ugm.ac.id
}

\begin{abstract}
Abstrak. Kerusakan bangunan pasca gempa bumi menghasilkan limbah berupa reruntuhan bangunan (reusable material) yang tidak dimanfaatkan secara maksimal, sehingga memerlukan adanya pemanfaatan limbah reruntuhan bangunan tersebut sebagai material untuk membangun bangunan baru. Pada Penelitian ini dilakukan pengembangan material bangunan untuk mesin 3D Printer dengan memanfaatkan material sisa reruntuhan (reusable concrete material). Pembuatan kombinasi material menggunakan design of experiment berupa $2^{\mathrm{k}}$ factorial design dengan menggunakan 2 faktor berupa variasi penambahan air dan superplaticizer, dengan 2 level berupa penambahan air sebesar $15 \mathrm{ml}$ dan $25 \mathrm{ml}$ dan superplaticizer $1 \mathrm{ml}$ dan $2 \mathrm{ml}$ dengan respon berupa kemampuan bentuk material. Hasil penelitian didapatkan bahwa run time 1 dan 2 mampu membentuk second layers tetapi run time 1 adanya ketidak-kontinuan material sedangkan run time 3 dan 4 tidak mampu membentuk second layers sehingga run time 2 yang memiliki kontinu dan kemampuan bentuk second layers.
\end{abstract}

Kata kunci : Reusable Concrete, 3D Printer, Kemampuan bentuk.

\section{Pendahuluan}

Badan Nasional Penanggulangan Bencana (BNPB) Indonesia menyatakan bahwa pada tahun 2001 hingga 2020 telah terjadi 278 peristiwa gempa bumi yang mengakibatkan sejumlah kerusakan pada bangunan [1]. Sisa reruntuhan bangunan yang diakibatkan bencana gempa bumi dapat dimanfaatkan menjadi waste building material. Pemanfaatan material tersebut bertujuan untuk mempercepat proses rekonstruksi bangunan dan menghemat biaya. Material sisa reruntuhan dipisahkan antara puing bangunan lainnya sebelum digunakan, sehingga dapat menghasilkan beton berkualitas tinggi dan tahan lama [2]. Pemanfaatan material sisa reruntuhan memerlukan pengolahan khusus, baik secara konvensional maupun dengan bantuan mesin. Penggunaan material sisa reruntuhan juga dapat menguntungkan pada wilayah-wilayah tertentu yang tidak memiliki sumber daya alam berupa pasir dan batu-batuan [3]

Proses pemulihan pasca gempa bumi membutuhkan waktu yang cukup lama dan menjadi penting, dikarenakan adanya kebutuhan terhadap mekanisme kerjasama yang mampu memberikan arahan pada tataran teknis dan strategis dalam melakukan rekonstruksi [4]. Contoh kasus proses pemulihan pasca gempa di Aceh dan Nias membutuhkan waktu selama 48 bulan. Hal tersebut dikarenakan proses pemulihan membutuhkan material, proses pengerjaan dan tenaga kerja [5]. Mesin 3D Printer dapat 
digunakan untuk mempersingkat proses pengerjaan konstruksi bangunan yang ramah lingkungan, penggunaan biaya yang lebih rendah dan proses transportasi peralatan yang lebih mudah [6]. Mesin 3D Printer berkerja dengan cara membuat benda secara layer by layer [7]. Belum tersedianya material yang umum digunakan untuk mesin 3D Printer menjadi salah satu permasalahan, sehingga diperlukan pengembangan komposisi material yang dapat digunakan untuk mesin 3D Printer bangunan serta menghasilkan hasil printing yang optimal. Material yang diperlukan sebagai komposisi pembuatan concrete untuk mesin 3D Printer yaitu semen, pasir, silica fume dan micro-fibres [8]. Selain itu, teknologi 3D Printer bangunan masih memerlukan pengembangan untuk menghasilkan hasil printing yang inovatif dan optimal dalam proses percetakkan, Skema proses 3D Printer untuk konstruksi dapat dilihat gambar $1[8]$.

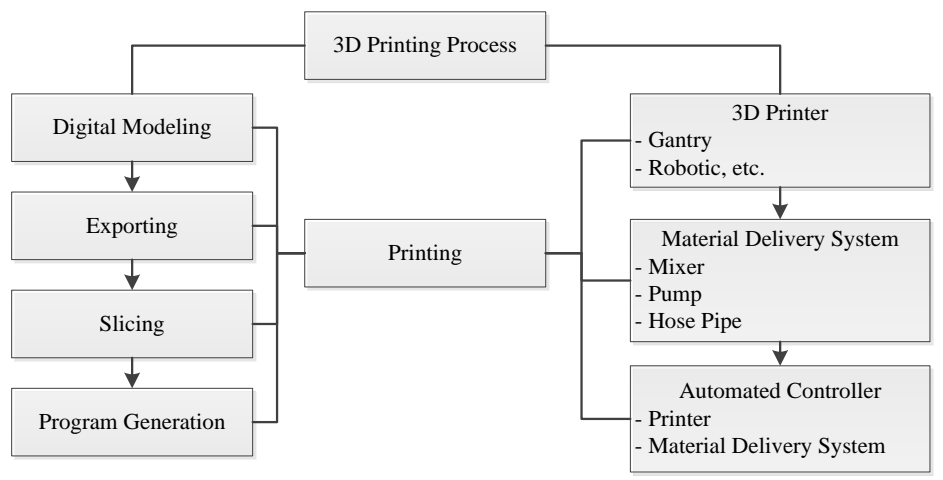

Gambar 1. Proses 3D Printer untuk konstruksi [8]

Material sisa reruntuhan bangunan akibat gempa bumi tidak dapat digunakan sepenuhnya sehingga membutuhkan bahan-bahan lain untuk dikombinasikan dengan material sisa reruntuhan bangunan agar proses rekonsruksi tidak memakan dana yang besar [3]. Sehingga pada penelitian ini membahas mengenai pengembangan material bangunan untuk mesin 3D Printer dengan memanfaatkan reusable concrete material, material tambahan yang digunakan pada penelitian ini adalah air, semen, reusable material, fly ash dan superplasticizer. Penelitian ini dilakukan di Laboratorium Desain Produk dan Bioceramics Fakultas Teknik Universitas Gadjah Mada.

\section{Metode Penelitian}

\subsection{Alur penelitian}

Adapun tahapan yang dilakukan pada penelitian ini dapat dilihat pada gambar 2. Penelitian dimulai dengan melakukan studi literatur mengenai material dan mesin 3D Printer yang digunakan dalam proses rekonstruksi bangunan. Kemudian dilakukan pilot study yang didasarkan pada penelitian yang telah dilakukan, sehingga didapatkan kombinasi faktor, level dan respon. Kemudian dilakukan pembuatan Design of Experiment (DoE), proses pembuatan material dilakukan sesuai dengan DoE. Kemudian dilakukan proses ekstruksi dengan menggunakan piping bag sebagai model sistem ektruksi pada sistem ekstruder mesin 3D Printer. Pengolahan data dilakukan untuk mendapatkan kombinasi yang optimal dari DoE, kemudian dilakukan penarikan kesimpulan berdasarkan eksperimen yang telah dilakukan. 


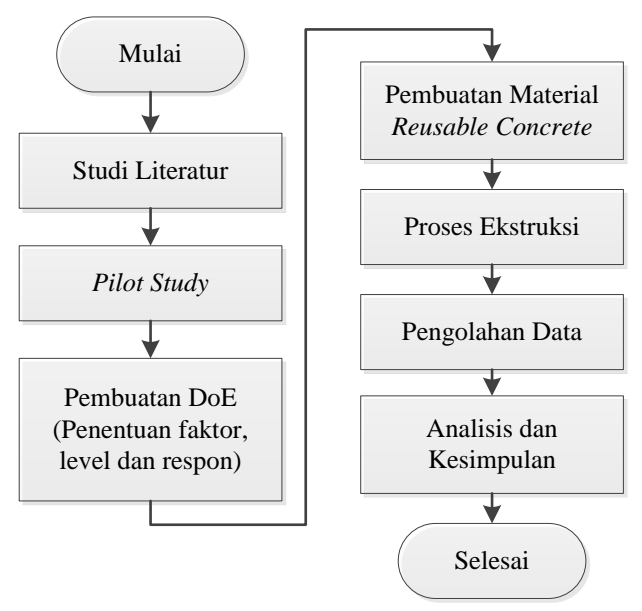

Gambar 2. Diagram Alur Penelitian

Metode DoE yang digunakan yaitu $2^{\mathrm{k}}$ factorial design untuk membuat kombinasi material (gambar 2). $2^{\mathrm{k}}$ Factorial design berguna dalam pengembangan dan peningkatan proses [10].

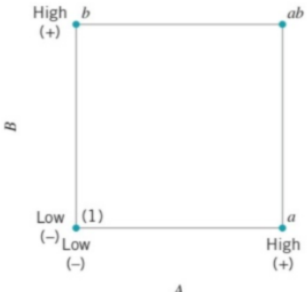

(a)

\begin{tabular}{cccccc}
\hline & & \multicolumn{4}{c}{ Factorial Effect } \\
\cline { 3 - 6 } Run & & $\boldsymbol{I}$ & $\boldsymbol{A}$ & $\boldsymbol{B}$ & $\boldsymbol{A B}$ \\
\hline 1 & $(1)$ & + & - & - & + \\
2 & $a$ & + & + & - & - \\
3 & $b$ & + & - & + & - \\
4 & $a b$ & + & + & + & + \\
\hline
\end{tabular}

(b)

Gambar 3. (a) Design geometry dan test matrix, (b) Interaksi Parameter

\subsection{Pembuatan Material}

Lee et al. (2012) melakukan pengembangan material untuk 3D Printer konstruksi dengan komposisi berupa sand-binder dengan rasio 3:2, yang terdiri dari 70\% semen, 20\% fly ash dan 10\% silica fume, dengan rasio penggunaan air sebesar 0,26 dan penambahan cairan superplaticizer $1 \%$ dan retarder $0,5 \%$, kombinasi campuran tersebut dapat keluar melalui nozzle dengan diameter $9 \mathrm{~mm}$ dan dapat membentuk 61 layers dengan kuat tekan sebesar $110 \mathrm{MPa}$ [11]. Malaeb et al. (2015) mengembangkan material untuk 3D Printer konstruksi dengan komposisi berupa 125 gr semen, 80 gr pasir dan 160 gr agregat halus dengan perbandingan rasio w/c 0,39, superplasticizer sebesar $1 \mathrm{ml}$ dan accelerator serta $0,625 \mathrm{ml}$ retarder. Komposisi ini menghasilkan aliran yang kontinu dengan diameter nozzle $2 \mathrm{~cm}$ dan menghasilkan kuat tekan sebesar $42 \mathrm{MPa}$ [12]. Pada penelitian ini menggunakan semen dan fly ash sebesar 45,3\% (w/w) dari agregat halus (reusable material), sedangkan pada penelitian Lee et al. (2012) komposisi semen, fly ash dan silica foam sebesar 66,67\% (w/w) dari agregat (pasir). Pada penelitian Malaeb et al. (2015) menggunakan perbandingan semen sebesar 63,3\% (w/w) dari agregat. Pada hasil pilot study penggunaan semen mengkombinasikan komposisi semen pada penelitian Lee et al. (2012) dan Malaeb et al. (2015) menghasilkan komposisi material untuk reusable material yang belum maksimal. Pada penentuan penggunaan air sebelum resting didapatkan komposisi air sesuai penelitian Lee et al. (2012) dan Malaeb et al. (2015), dan didapatkan hasil material memiliki viskositas yang terlalu rendah, sehingga penggunaan air dikurangi menjadi 37,5\% (v/w) dari reusable material, penambahan superplasticizer dilakukan pada tahap ini kemudian dilakukan pengadukan sampai campuran material merata/homogen. 


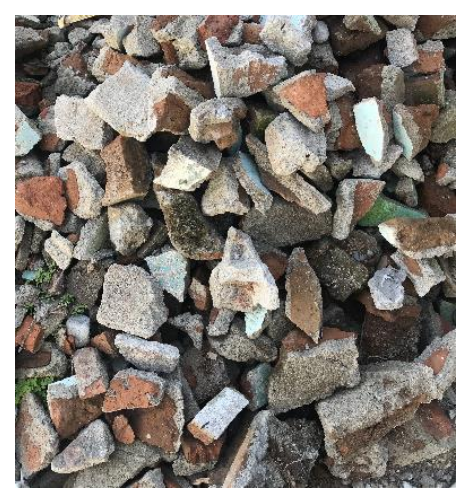

Gambar 4. Reruntuhan bangunan Pasca Gempa Bumi

Material sisa reruntuhan bangunan akibat gempa bumi (gambar 4) dipisahkan dengan puing-puing lainnya. Kemudian dihancurkan dan diayak menggunakan mesh 1x1 mm sehingga dapat dijadikan agregat kasar dan halus yang dapat diolah kembali dengan tambahan material lainnya.

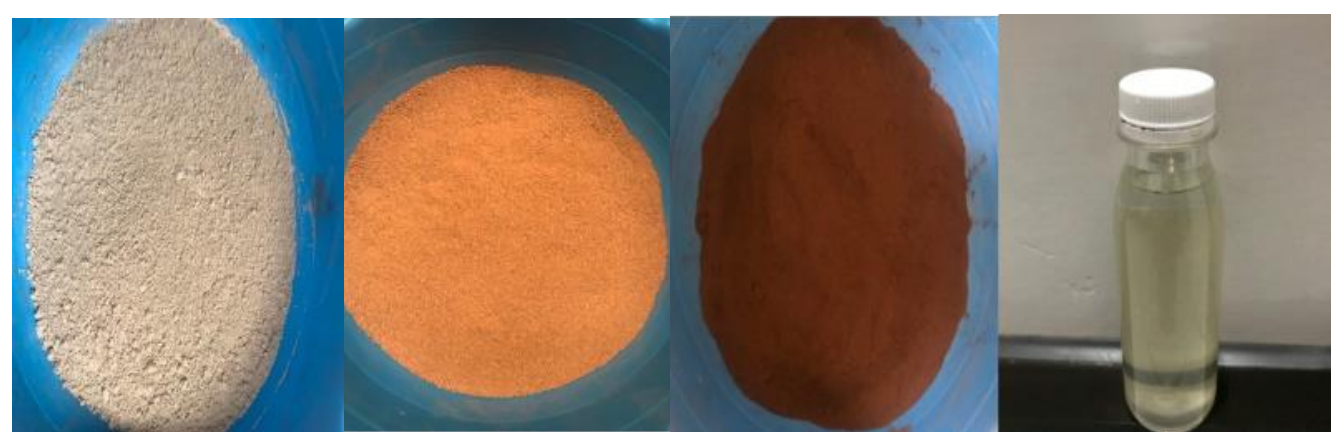

(a) (c) (d)

Gambar 5. (a) semen, (b) sisa reruntuhan (reusable concrete material), (c) fly ash, (d) superplaticizer

Hasil analisis penelitian yang telah dilakukan didapatkan kombinasi komposisi material (tabel 1) yang dijadikan bahan tambah untuk main material berupa material sisa reruntuhan (reusable material). Pada pilot study yang telah dilakukan didapatkan bahwa material dengan komposisi tersebut memerlukan proses resting selama 60 menit. resting merupakan proses mendiamkan material pada suhu ruang agar viskositas material menjadi lebih tinggi, sehingga dapat ditambahkan air untuk mendapatkan viskositas material yang menjadikan material dapat keluar dari nozzle dengan diameter $20 \mathrm{~mm}$.

Tabel 1. Kombinasi Material Reusable Concrete

\begin{tabular}{cccc}
\hline Resuable material (gr) & Semen (gr) & Fly Ash (gr) & Air (ml) \\
\hline 300 & 100 & 36 & 110
\end{tabular}

Adapun faktor yang digunakan yaitu variasi penggunaan superplaticizer sebesar dengan level $1 \mathrm{ml}$ dan 2 $\mathrm{ml}$ dan variasi penambahan air dengan level $15 \mathrm{ml}$ dan $25 \mathrm{ml}$ setelah resting material (Tabel 2).Adapun respon yang digunakan berupa kemampuan bentuk material untuk membentuk susunan layer by layer secara visual.

Tabel 2. Design of experiment 


\begin{tabular}{ccccc}
\hline Run Time & \multicolumn{2}{c}{ Level } & Penambahan air & Superplaticizer \\
\hline 1 & +1 & +1 & $15 \mathrm{ml}$ & $1 \mathrm{ml}$ \\
2 & +1 & -1 & $15 \mathrm{ml}$ & $2 \mathrm{ml}$ \\
3 & -1 & +1 & $25 \mathrm{ml}$ & $1 \mathrm{ml}$ \\
4 & -1 & -1 & $25 \mathrm{ml}$ & $2 \mathrm{ml}$ \\
\hline
\end{tabular}

Proses ekstruksi dilakukan dengan menggunakan piping bag sebagai alat simulasi sistem ekstruksi material pada saat keluar dari nozzle. Diameter lubang piping bag sebesar $20 \mathrm{~mm}$ (gambar 6). Adapun pengujian dilakukan dengan membentuk 4 layers untuk setiap run time.

Piping bag ditekan untuk mengeluarkan material keluar melalui nozzle. Sehingga didapatkan kemampuan material untuk keluar dari nozzle. Proses ekstruksi diarahkan untuk melakukan printing berupa garis dengan membuat ketinggian yang dilakukan dengan membuat layer

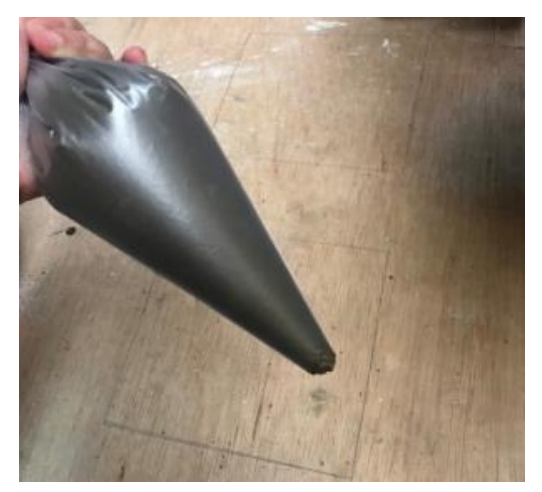

Gambar 6. Material pada piping bag

\section{Pembahasan}

Eksperimen yang telah dilakukan dengan memberikan treatment yang bervariasi didasarkan pada design of experiment dengan menggunakan $2^{\mathrm{k}}$ factorial design didapatkan hasil penelitian (tabel 3 ) dengan hasil visual (gambar 7).

Tabel 3. Hasil Penelitian

\begin{tabular}{ccc}
\hline $\begin{array}{c}\text { Run } \\
\text { time }\end{array}$ & \multicolumn{2}{c}{$\begin{array}{c}\text { Kemampuan bentuk } \\
\text { (4 layers) }\end{array}$} \\
\hline 1 & +1 & Ya \\
\hline 2 & +1 & Ya \\
\hline 3 & -1 & Tidak \\
\hline 4 & -1 & Tidak \\
\hline
\end{tabular}




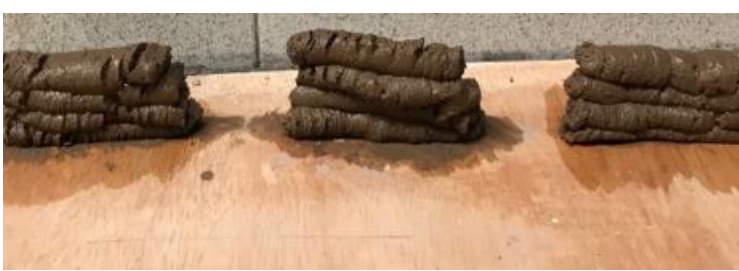

(a)

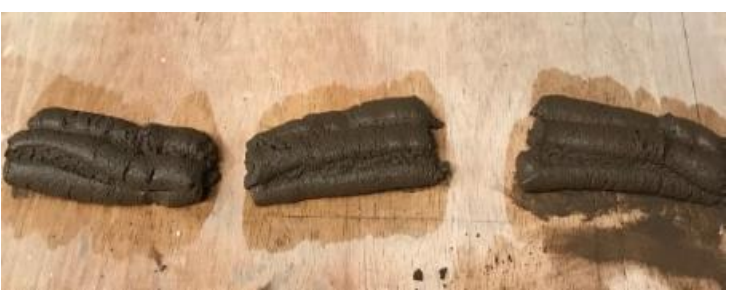

(c)

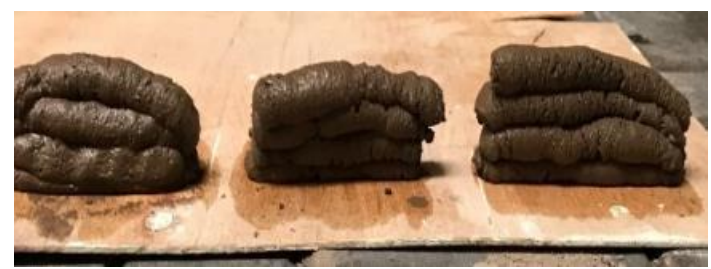

(b)

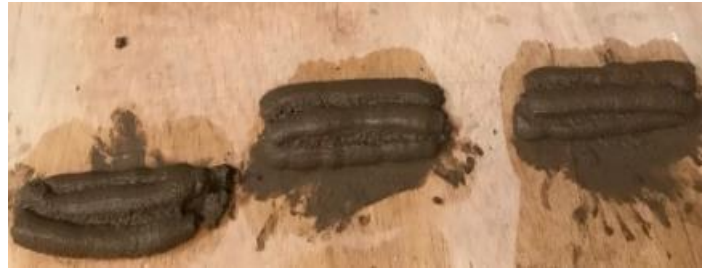

(d)

Gambar 7. (a) Visual run time 1, (b) Visual run time 2, (c) Visual run time 3 dan (d) Visual run time 4

Dari hasil penelitian didapatkan hasil printing pada run time 1 dapat membentuk 4 layers dengan hasil berupa adanya ketidak-kontinuan material ketika proses printing dilakukan. Pada run time 2 secara visual dapat membentuk 4 layers. Run time 3 dan run time 4 didapatkan hasil material tidak mampu membentuk second layer, hal tersebut disebabkan karena material memiliki viskositas rendah yang mengakibatkan tidak membentuk second layers. Secara visual Run time 2 yang memiliki kontinu dan kemampuan bentuk second layer dengan penambahan air sebesar $15 \mathrm{ml}$ dan penggunaan superplaticizer sebesar $2 \mathrm{ml}$.

\section{Kesimpulan}

Pembuatan kombinasi material menggunakan design of experiment berupa $2^{\mathrm{k}}$ factorial design dengan menggunakan 2 faktor berupa variasi penambahan air dan superplaticizer, dengan 2 level berupa penambahan air sebesar $15 \mathrm{ml}$ dan $25 \mathrm{ml}$ dan superplaticizer $1 \mathrm{ml}$ dan $2 \mathrm{ml}$ dengan respon berupa kemampuan bentuk. Hasil penelitian ketika dilakukan penambahan air sebesar $15 \mathrm{ml}$ dan superplaticizer $1 \mathrm{ml}$ dan $2 \mathrm{ml}$ secara visual dapat membentuk 4 layers tetapi terdapat perbedaan pada penggunaan superplaticizer $1 \mathrm{ml}$, dapat membentuk tetapi masih terlihat tidak kontinu dan hasil penelitian ketika dilakukan penambahan air sebesar $25 \mathrm{ml}$ dan superplaticizer $1 \mathrm{ml}$ dan $2 \mathrm{ml}$ tidak dapat membentuk second layers disebabkan material memiliki viskositas yang rendah yang mengakibatkan tidak membentuk second layers. Run time 1 dan 2 mampu membentuk second layer tetapi run time 1 adanya ketidak-kontinuan material sedangkan run time 3 dan 4 tidak mampu membentuk second layer. Material reusable concrete dapat digunakan untuk 3D Printing konstruksi dan dapat dilakukan optimasi parameter serta pengujian dengan kombinasi material yang telah dilakukan.

\section{Ucapan Terima Kasih}

Penelitian ini didukung oleh Departemen Teknik Mesin dan Industri, Fakultas teknik, Universitas Gadjah Mada. Terimakasih kepada Laboratorium Desain Produk dan Bioceramics Fakultas Teknik Universitas Gadjah Mada.

\section{Daftar Pustaka}

[1] BNPB 2020 Badan nasional penanggulangan bencana: dara tahunan bencana alam di indonesia tahun 2001-2020, http://bnpb.cloud/dibi/tabel1a

[2] Zhao X, Wang Q, and Liu Y 2013 A review on the properties of bricks prepared with recycled waste materials - Postearthquake waste consideration Advanced Materials Research 661 108-11

[3] Wibowo A P 2015 Aplikasi material bekas pakai pada rekonstruksi rumah tinggal pasca bencana alam gempa bumi 9(KoNTekS 9) 7-8 
[4] Sagala S, Situngkir F and Wimbarda R 2019 Interaksi Aktor dalam Rekonstuksi Rumah Pascabencana Gempa Bumi 29(2) 217-226

[5] Ophiyandri T 2015 Community-based post-disaster housing reconstruction: examples from indonesia' Post-Disaster Reconstruction of the Built Environment: Rebuilding for Resilience ch.6 91-116

[6] Hager I, Golonka A, and Putanowicz R 2016 3D Printing of buildings and building components as the future of sustainable construction Procedia Engineering 151 292-99

[7] Tontowi A E 2016 Desain Produk Inovatif dan Inkubasi Bisnis Kompetitif Gadjah Mada University Press Yogyakarta

[8] Tay Y W D, Panda B, Paul S C, Mohamed N A N, Tan M J and Leong K F 2017 3D printing trends in building and construction industry: a review Virtual and Physical Prototyping 12(3) 261-76

[9] Valente M, Sibai A and Sambucci M 2019 Extrusion-based additive manufacturing of concrete products: revolutionizing and remodeling the construction industry Journal of Composites Science, 3(3) 88

[10] Montgomery DC 2001 Introduction To Statistical Quality Control 6th Wiley Missouri

[11] Le T T, Austin S A, Lim S, Buswell R A, Gibb A G F and Thorpe T 2012 Mix design and fresh properties for high-performance printing concrete Materials and Structures/Materiaux et Constructions 45(8) 1221-32

[12] Malaeb Z, Hachem H, Tourbah A, Maalour T, Zarwi N E and Hamzah F 2015 3D concrete printing: machine and mix design International Journal of Civil Engineering and Technology 6 1422. 
